\title{
Effects of icotinib on early-stage non-small-cell lung cancer as neoadjuvant treatment with different epidermal growth factor receptor phenotypes
}

This article was published in the following Dove Press journal:

OncoTargets and Therapy

22 March 2016

Number of times this article has been viewed

\author{
Tao Wang' \\ Yang Liu' \\ Bin Zhou' \\ Zhi Wang' \\ Naichao Liang' \\ Yundong Zhang' \\ Zhouhuan Dong 2 \\ Jie $\mathrm{Li}^{2}$
}

'Department of Thoracic Surgery, 2Department of Pathology, People's Liberation Army General Hospital, Beijing, People's Republic of China

Correspondence: Tao Wang Department of Thoracic Surgery, People's Liberation Army General Hospital, 28 Fuxing Road, Haidian District, Beijing, People's Republic of China

Tel +861066875514

Fax +86 10 678I 7113

Email doctorwt30I@I63.com
Purpose: Epidermal growth factor receptor-tyrosine kinase inhibitors (EGFR-TKIs) have demonstrated efficacy in treating advanced non-small-cell lung cancer (NSCLC). Preliminary findings suggested that EGFR-TKIs might also be beneficial in neoadjuvant therapy in treating NSCLC. Therefore, this study aimed to evaluate the efficacy and safety of neoadjuvant therapy with icotinib in patients with early-stage NSCLC.

Patients and methods: We retrospectively reviewed the medical history of patients who were initially diagnosed with stage IA-IIIA NSCLC and were under icotinib administration before surgery between December 2011 and December 2014. Tumor assessment was conducted between the second and fourth week from initial icotinib treatment. The association between personal characteristics, smoking status, disease stage, EGFR mutation status, and clinical outcomes were investigated using multivariate logistic regression analysis.

Results: A total of 67 patients with NSCLC were reviewed, and approximately half (38/67) of them were identified as having EGFR-mutant tumors. The overall response rate of all patients was $26.7 \%$ at $2-4$ weeks' assessment. Multivariate analysis showed that female sex $(38.5 \%$ versus $10.7 \%$ in males, $P=0.028)$ and EGFR mutation status $(42.1 \%$ versus $6.9 \%$ in EGFR wild type, $P=0.011)$ were independent predictive factors. The analysis also showed that the most common adverse effects were rash (43.3\%) and dry skin (34.4\%), which were tolerable.

Conclusion: Icotinib induced clinical response with minimal toxicity as neoadjuvant treatment in early NSCLC, especially in patients with common EGFR mutations. Further studies are warranted to confirm our findings.

Keywords: non-small-cell lung cancer, epidermal growth factor receptor, tyrosine kinase inhibitor, neoadjuvant

\section{Introduction}

Lung cancer is the most commonly diagnosed cancer in the People's Republic of China, with approximately 650,000 new cases diagnosed in 2011. ${ }^{1}$ Approximately, $85 \%$ of these tumors are non-small-cell lung cancers (NSCLCs), and 25\%-30\% of the NSCLCs are potentially curable with a multimodality approach. ${ }^{2}$ However, the 5-year survival rates still remain low, with $67 \%$ for stage I, $54 \%$ for stage II, and $40 \%$ for stage III. ${ }^{3}$

Neoadjuvant therapy might be considered as effective in reducing tumor size, increasing operability, and eradicating micrometastases. A meta-analysis of 13 randomized trials, which was conducted by Burdett et al, reported that neoadjuvant chemotherapy was associated with improved survival in operable patients, with $5 \%$ absolute benefit at 5 years. ${ }^{4}$ However, treatment-associated toxicities and a delay in the surgical procedure also limited the use of chemotherapy in a neoadjuvant setting. Since, several 
randomized Phase III clinical trials involving metastatic NSCLC that harbored epidermal growth factor receptor (EGFR) mutations revealed that EGFR-tyrosine kinase inhibitors (TKIs), which function as molecularly targeted agents, are superior to chemotherapy. ${ }^{5}$ The National Comprehensive Cancer Network and European Society for Medical Oncology Guidelines recommend EGFR-TKIs as a standard first-line treatment in this population. ${ }^{6,7}$ Given their activity in advanced disease and tolerable toxicity profile, EGFR-TKIs could have potential benefits as neoadjuvants and/or adjuvants in treating early EGFR-mutated NSCLC.

Icotinib, which is developed in the People's Republic of China, is a small-molecule EGFR-TKI. A randomized Phase III study demonstrated that the efficacy of icotinib was not inferior to gefinitib. ${ }^{8}$ In addition, icotinib was approved by the China Food and Drug Administration as second- or third-line treatment for advanced NSCLC in June 2011 and as a first-line therapy for EGFR-mutant NSCLC recently.

Therefore, the present study aimed to retrospectively evaluate the efficacy and safety of icotinib in treating patients living with early-stage NSCLC during a 2-4 weeks preoperative window. Moreover, potential predictive markers are also investigated in this analysis.

\section{Materials and methods Study design and patients}

A total of 91 patients with a diagnosis of stage IA-IIIA NSCLC and who were administered icotinib (125 mg; Betta Pharmaceuticals Co., Ltd, Hangzhou, People's Republic of China) thrice daily preoperatively were recruited between December 2011 and December 2014 in the People's Liberation Army General Hospital. Eligible patients for this retrospective study were selected in accordance with the following inclusion criteria: patients had dimensionally measurable lesion in accordance with Response Evaluation Criteria in Solid Tumors (RECIST) criteria; had not received chemotherapy or targeted drug; had tumor assessment at 2-4 weeks after receiving icotinib; and had assessed EGFR mutational status. In the end, a total of 24 patients were excluded from this analysis for the following reasons: operations were earlier than planned, the icotinib duration was less than 2 weeks $(n=23)$, and unknown EGFR mutational status $(n=1)$. Accordingly, 67 patients were enrolled in this analysis, 54 of those had surgical resection after 2 weeks' treatment, and 13 patients underwent surgery after the fourth week's evaluation.

This retrospective study was approved by the People's Liberation Army General Hospital Review Board. Patient's clinical records were anonymized and de-identified prior to analysis.

\section{Patient characteristics and evaluation of therapeutic outcomes and toxicity}

Patient characteristics, including EGFR mutation status, were retrospectively obtained from medical records. EGFR mutational status was analyzed through the amplification refractory mutation system method (Beijing ACCB Biotech Ltd, Beijing, People's Republic of China) using surgical tissue sample. Tumor responses were interpreted by the same radiologist in accordance with RECIST criteria, version 1.1. ${ }^{9}$ Tumor responses were classified as complete response, partial response, stable disease, and progressive disease. Toxicities were categorized into five grades, namely 0-4, in accordance with "Common Terminology Criteria for Adverse Events" (CTCAE4.0), which was established by the National Cancer Institute of America. ${ }^{10}$

\section{Statistical analysis}

All the data analyses in this study were conducted using SPSS 17.0 (SPSS Inc., Chicago, IL, USA). All statistical tests were two-tailed, and $\alpha$ was set at 0.05 to define statistical significance. Baseline characteristics of the study population were described and compared using independent samples $t$-test. The chi-square test and Fisher's exact test were performed to explore the difference in general characteristics, such as sex, age, smoking history, histology, and staging, between those with EGFR-mutant tumors and wild-type patients. In addition, the correlation between characteristics and objective response rate (ORR) was also investigated. In order to identify independent factors, multivariate logistic regression model was built.

\section{Results \\ General characteristics of patients and EGFR phenotype}

The clinical characteristics of the study population are listed in Table 1. A total of 28 male (41.8\%) and 39 female (58.2\%) patients with a median age of 59 years were included in the analysis. Among those, 42 (62.7\%) were never smokers and $25(37.3 \%)$ had a smoking history. The majority were diagnosed with adenocarcinoma (95.5\%). Among the eligible patients, $22(32.8 \%)$ were diagnosed with stage IA, $30(44.8 \%)$ with stage IB, five $(7.46 \%)$ with stage IIA, and ten $(14.9 \%)$ with stage IIIA disease. Among the 38 (56.7\%) patients harboring EGFR mutations, 15 carried deletion in exon 19, 16 carried the L858R mutation in exon 21, and seven carried the mutation in exon 20 , whereas the remaining 29 (43.3\%) patients were confirmed as wild-type EGFR. The clinical characteristics showed no significant difference between EGFR-mutated and wild-type patients. 
Table I General characteristics of the 67 patients

\begin{tabular}{|c|c|c|c|c|}
\hline Variables & $\begin{array}{l}\text { All patients } \\
(n=67)\end{array}$ & $\begin{array}{l}\text { EGFR mutation } \\
(n=38)\end{array}$ & $\begin{array}{l}\text { EGFR wild type } \\
(n=29)\end{array}$ & $P$-value \\
\hline Sex & & & & 0.347 \\
\hline Male & 28 (4I.8\%) & 14 & 14 & \\
\hline Female & 39 (58.2\%) & 24 & 15 & \\
\hline Age & & & & 0.352 \\
\hline Median (years) & $59(37-78)$ & $57.5(43-78)$ & $59(37-77)$ & \\
\hline$<65$ & $50(74.6 \%)$ & 30 & 20 & \\
\hline$\geq 65$ & 17 (25.4\%) & 8 & 8 & \\
\hline Smoking & & & & 0.105 \\
\hline Yes & $25(37.3 \%)$ & 11 & 14 & \\
\hline No & $42(62.7 \%)$ & 27 & 15 & \\
\hline Histology & & & & 0.574 \\
\hline Adeno & 64 (95.5\%) & 37 & 27 & \\
\hline Squamous & $3(4.5 \%)$ & 1 & 2 & \\
\hline Stage & & & & 0.58 \\
\hline IA & $22(32.8 \%)$ & 15 & 7 & \\
\hline IB & $30(44.8 \%)$ & 15 & 15 & \\
\hline$\| \mathrm{A}$ & $5(7.5 \%)$ & 3 & 2 & \\
\hline IIIA & $10(14.9 \%)$ & 5 & 5 & \\
\hline EGFR mutations & & & & NA \\
\hline Exon 19 deletion & NA & 15 & NA & \\
\hline \multirow[t]{2}{*}{ Exon 21 L858R exon $20^{a}$} & NA & 16 & NA & \\
\hline & NA & 7 & NA & \\
\hline
\end{tabular}

Note: aExon 20 mutation, including 5 Q787Q, I V8I9V, I Y774-776ins.

Abbreviations: Adeno, adenocarcinoma; Squamous, squamous-cell carcinoma; EGFR, epidermal growth factor receptor; NA, not applicable.

\section{Evaluation of clinical response}

At 2-4 weeks' assessment via computed tomography (CT), 18 out of the 67 patients achieved partial response and 49 had stable disease. The ORR was $26.7 \%$. The association between the clinicopathological factors and early response was analyzed and is presented in Table 2 . The ORR was significantly higher among the females $(38.5 \%$ in females versus $10.7 \%$ in males), nonsmokers ( $35.7 \%$ in nonsmokers versus $12 \%$ in smokers), patients with EGFR-mutant tumors ( $42.1 \%$ in mutant versus $6.9 \%$ in wild-type patients; Table 3 ), and those with rash $(41.4 \%$ in rash versus $15.8 \%$ in no rash patients) when compared with their counterparts $(P<0.05)$. However, the statistical analysis showed no significant association between the clinical response to icotinib administration and some of the patient characteristics, including age, pathological type, and disease stage. Multivariate logistic regression analysis demonstrated that female sex (38.5\% versus $10.7 \%$ in males, $P=0.028,95 \%$ confidence interval [CI]: 1.19-22.68) and EGFR mutational status (42.1\% versus $6.9 \%$ in EGFR wild-type, $P=0.011,95 \%$ CI: $1.62-42.61)$ were independent predictive factors. Furthermore, among the 38 patients with an EGFR mutation, the females also showed a better response (54.2\%) than their male counterparts $(21.4 \%, P=0.049)$. In addition, the results of the analysis also indicated that patients with common type of EGFR mutation (ORR was $60 \%$ in exon 19 deletion and $43.8 \%$ in exon 21 L858R mutation) received greater benefits than those with exon 20 mutations (ORR was $0 \%, P=0.008$ ). In addition, no significant difference was observed between patients with exon 19 deletion and those with exon 21 L858R mutation $(P=0.366)$.

With regard to the change in tumor's longest diameter, the percentage change upon evaluation at 2-4 weeks from baseline was $-19.6 \% \pm 2 \%(95 \% \mathrm{CI}:-23.6 \%,-15.6 \%)$ in all the patients. When differences in the EGFR status were compared, we recorded significant percentage changes of $-26.15 \% \pm 2.4 \%$ and $-10.92 \% \pm 2.67 \%$ in EGFR-mutated and wild-type patients, respectively $(P<0.001$; Table 4$)$. Furthermore, among those with an EGFR mutation, the percentage shrinkage was $-28.6 \% \pm 2.4 \%$ (95\% CI: $-33.7 \%,-23.5 \%)$ in exon 19 deletion, $-30.6 \% \pm 4.13 \%$ (95\% CI: $-39.4 \%,-21.8 \%)$ in exon 21 L858R mutation $(P=0.68)$, and $-10.6 \% \pm 4.1 \%$ (95\% CI: $-20.7 \%,-0.6 \%$ ) in exon 20 mutation.

\section{Adverse effects of 2-4 weeks' icotinib treatment for patients with early-stage NSCLC}

Among the eligible population, 45 (67.2\%) patients experienced adverse drug reactions, with the most common adverse effects being skin rash and skin dryness. It was observed that 29 (43.3\%) patients had skin rash (27 patients had grade 1 
Table 2 Association of clinicopathological factors and molecular characteristics with tumor response to short-term icotinib treatment

\begin{tabular}{|c|c|c|c|c|c|}
\hline \multirow{2}{*}{$\begin{array}{l}\text { Clinical } \\
\text { characteristics }\end{array}$} & \multicolumn{5}{|l|}{ Partial response } \\
\hline & $\begin{array}{l}\text { All patients }(n=67) \text {, } \\
n(\%)\end{array}$ & $P$-value & $\begin{array}{l}\text { EGFR mutation } \\
(n=38), n(\%)\end{array}$ & $P$-value & $\begin{array}{l}\text { EGFR wild type } \\
(n=29), n(\%)\end{array}$ \\
\hline Sex & & 0.011 & & 0.049 & \\
\hline Male & $3(10.7 \%)$ & & $3(21.4 \%)$ & & 0 \\
\hline Female & 15 (38.5\%) & & I3 (54.2\%) & & $2(13.3 \%)$ \\
\hline Age & & 0.762 & & 0.767 & \\
\hline$<65$ & I3 (26\%) & & $13(43.3 \%)$ & & 0 \\
\hline$\geq 65$ & 5 (29.4\%) & & $3(37.5 \%)$ & & $2(22.2 \%)$ \\
\hline Smoking & & 0.034 & & 0.237 & \\
\hline Yes & $3(12 \%)$ & & $3(27.3 \%)$ & & 0 \\
\hline No & 15 (35.7\%) & & $13(48.1 \%)$ & & $2(13.3 \%)$ \\
\hline Histology & & 0.558 & & I & \\
\hline Adeno & I8 (28.1\%) & & $16(43.2 \%)$ & & $2(7.4 \%)$ \\
\hline Squamous & $0(\%)$ & & 0 & & 0 \\
\hline Stage & & 0.358 & & 0.484 & \\
\hline I & $16(30.2 \%)$ & & 14 (46.7\%) & & $2(8.7 \%)$ \\
\hline IIA & I (25\%) & & I (33.3\%) & & 0 \\
\hline IIIA & I (I0\%) & & I (20\%) & & 0 \\
\hline Adverse effect & & 0.019 & & 0.154 & \\
\hline Skin rash & $12(4 \mathrm{I} .4 \%)$ & & II (52.4\%) & & I (I2.5\%) \\
\hline No skin rash & $6(15.8 \%)$ & & $5(29.4 \%)$ & & I (4.8\%) \\
\hline EGFR & & 0.001 & & & NA \\
\hline Mutations & 16 (42.1\%) & & & 0.008 & NA \\
\hline $19 \mathrm{Del}$ & NA & & $9(60 \%)$ & & NA \\
\hline $21 \mathrm{L858R}$ & NA & & $7(43.8 \%)$ & & NA \\
\hline 20 & NA & & 0 & & NA \\
\hline Wild type & $2(6.9 \%)$ & & NA & & NA \\
\hline
\end{tabular}

Abbreviations: Adeno, adenocarcinoma; Squamous, squamous-cell carcinoma; 19 Del, exon 19 deletion; 21 L858R, exon 21 L858R mutation; EGFR, epidermal growth factor receptor; NA, not applicable.

and two patients had grade 2$), 23$ (34.3\%) had dry skin (22 had grade 1 and one had grade 2$)$, nine (13.4\%) had grade 1 diarrhea, three had grade 1 oral ulcer, and one had grade 1 alopecia. However, these adverse drug reactions did not result in the discontinuation of icotinib treatment (Table 5).

Icotinib was administrated until the day before surgery in all the patients. Operations were performed via a video-assisted thoracoscopy or a lateral incision approach. We observed that the main difference from the conventional operation was

Table 3 Comparison of overall response between EGFR-mutated and wild-type patients upon evaluation at 2-4 weeks

\begin{tabular}{|c|c|c|c|}
\hline $\begin{array}{l}\text { Best tumor change } \\
\text { (RECISTI.I) }\end{array}$ & $\begin{array}{l}\text { EGFR mutation } \\
(n=38)\end{array}$ & $\begin{array}{l}\text { EGFR wild type } \\
(n=29)\end{array}$ & $P$-value \\
\hline$C R(n)$ & 0 & 0 & \\
\hline PR (n) & 16 & 2 & \\
\hline$S D(n)$ & 22 & 27 & \\
\hline PD (n) & 0 & 0 & \\
\hline ORR & $42.1 \%$ & $6.9 \%$ & 0.001 \\
\hline
\end{tabular}

Note: RECISTI.I signifies "no confirmation measurement".

Abbreviations: CR, complete response; PR, partial response; SD, stable disease; $\mathrm{PD}$, progressive disease; ORR, overall response rate; RECIST, Response Evaluation Criteria in Solid Tumors; EGFR, epidermal growth factor receptor. that neoadjuvant therapy led to tissue adhesion, especially in separating pulmonary vessels and vascular sheath, and vascular fragility increased when ligating blood vessels, but no vascular rupture occurred. However, the surgical incision healed well.

\section{Follow-up}

Until the last follow-up on December 31, 2014, the median follow-up time was 20 months (range: 1-36 months). Fifty patients

Table 4 Comparison of the tumor shrinkage upon evaluation at 2-4 weeks from baseline between EGFR-mutated and wild-type patients

\begin{tabular}{|c|c|c|c|}
\hline $\begin{array}{l}\text { Percentage tumor } \\
\text { change (longest } \\
\text { diameter) }\end{array}$ & $\begin{array}{l}\text { EGFR mutation } \\
\text { (\%), } n=38\end{array}$ & $\begin{array}{l}\text { EGFR wild type } \\
\text { (\%), } n=29\end{array}$ & $P$-value \\
\hline Mean $\pm S D$ & $-26.15 \pm 2.4$ & $-10.92 \pm 2.67$ & $<0.001$ \\
\hline Min, $\max$ & $-64.4,1.8$ & $-52.5,10.34$ & \\
\hline Median & -25.53 & -8.7 & \\
\hline QI, Q3 & $-27.27,-31.01$ & $-16.39,-5.44$ & \\
\hline
\end{tabular}

Abbreviations: EGFR, epidermal growth factor receptor; max, maximum; min, minimum; QI, first quartile; Q3, third quartile; SD, standard deviation. 
Table 5 Summary of the treatment-related adverse events

\begin{tabular}{llllll}
\hline Adverse events & Grade I, n (\%) & Grade 2, n (\%) & Grade 3, n (\%) & Grade 4, n (\%) & Total, n (\%) \\
\hline Acne/rash & $27(40.3)$ & $2(3)$ & 0 & 0 & $29(43.3)$ \\
Dry skin & $22(32.8)$ & $1(I .5)$ & 0 & 0 & $23(34.3)$ \\
Diarrhea & $9(13.4)$ & 0 & 0 & 0 & $9(13.4)$ \\
Oral ulcer & $3(4.5)$ & 0 & 0 & 0 & $3(4.5)$ \\
Alopecia & I (I.5) & 0 & 0 & 0 & $1(1.5)$ \\
\hline
\end{tabular}

received systemic adjuvant therapy, while 17 did not receive any treatment. Only five (7.5\%) patients experienced disease progression, and the disease-free survival rate was $10,15,16$, 18 , and 20 months, respectively. Two of them experienced disease relapse, and three had brain/bone metastases. A total of 62 patients remained disease free. The majority of patients are still alive, and the OS data has not matured. Only two died of brain metastases and adverse effects of chemotherapy, with OS being 30 and 24 months, respectively.

\section{Discussion}

The present study demonstrated that icotinib induced clinical response with minimal toxicity. In addition, it was associated with no additional surgical risk when utilized as a neoadjuvant therapy in treating early NSCLC. After 2-4 weeks' icotinib administration, the ORR was $26.7 \%$ in all the patients, $42.1 \%$ and $6.9 \%$ in those with an EGFR mutation and wild-type patients, respectively. While a pivotal study has reported on the relationship between EGFR mutations and TKI sensitivity since $2004,{ }^{11}$ multiple Phase III studies have confirmed a striking response and indicated longer progression-free survival (PFS) with EGFR-TKIs than with standard chemotherapy in advanced NSCLC with an EGFR mutation. ${ }^{5}$ In neoadjuvant therapy, EGFR-TKI remains hypothetical and needs strong evidence to confirm its efficacy in treating early NSCLC with an EGFR mutation. The results of the current study were consistent with those found in previous Phase II studies. For instance, a number of single arm, Phase II studies showed the benefits of EGFR-TKIs in neoadjuvant therapy. Lara-Guerra et al ${ }^{12}$ evaluated 36 patients with 17\% EGFR mutations who had been treated with gefitinib $250 \mathrm{mg}$ /day as neoadjuvant therapy for 28 days. The response rate among patients who harbored EGFR mutations was 50\%, which was only $11 \%$ in all the patients. Similar findings were also reported by Schaake et al, ${ }^{13}$ where 60 patients received preoperative erlotinib (150 mg) once daily for 3 weeks.

Traditionally, neoadjuvant chemotherapy is considered as the primary approach in treating NSCLC. Three randomized clinical trials (RCTs) demonstrated that the ORR was
$35 \%, 41 \%$, and $53 \%$ in the neoadjuvant chemotherapy arms, respectively. ${ }^{14-16} \mathrm{~A}$ meta-analysis by Pisters et al, ${ }^{15}$ which included ten RCTs, showed a significant survival advantage for those who received induction chemotherapy (hazard ratio [HR] $0.89, P=0.02)$. In addition, the current study further confirmed the findings of earlier studies, where an ORR of $42.1 \%$ was reported among those living with EGFR-mutated tumors. We considered EGFR-TKIs warranted evaluation of their potential role as neoadjuvant options by properly designed RCTs in NSCLC EGFR mutation population.

Among the 38 patients with EGFR-mutated lung cancer, 15 harbored exon 19 deletion, 16 had exon 21 L858R mutation, and seven harbored exon 20 mutation. Among those with common type of EGFR mutation, the ORR was $60 \%$ in exon 19 deletion and 43.8\% in L858R mutation at 2-4 weeks of evaluation. No partial response was observed in patients with exon 20 mutation. The current study revealed a different response rate between exon 19 deletion and exon 21 L858R (60\% versus 43.8\%, $P=0.366$ ) mutation; however, the difference was not statistically significant. Jackman et al and Riely et al indicated that mutations in both exons 19 and 21 were correlated with a promising clinical response to gefitinib or erlotinib. Moreover, patients with exon 19 deletions might show better response than those with exon 21 L858R mutations in terms of response rate, PFS, and OS. ${ }^{17,18}$ In CALGB 30406 study, the response rate of exon 19 deletion and exon 21 L858R mutation were $83 \%$ and $40 \%$, and the median PFS was 15.7 and 12.6 months, respectively, in erlotinib arm. ${ }^{19}$ The variation between exon 19 deletion and exon $21 \mathrm{~L} 858 \mathrm{R}$ mutation was further confirmed in a pooled analysis of LUX-Lung 3 and LUX-Lung 6 trials. ${ }^{20}$ When compared with traditional chemotherapy, sustainable survival benefits were observed among patients with exon 19 deletions, while no significant improvement was witnessed among those with exon 21 L858R mutations. The current study indicated that a difference might also exist in icotinib treatment and warrants further exploration in neoadjuvant therapy with EGFR-TKIs. Regarding those with exon 20 mutations, none achieved response, which further confirmed the findings from previous research work, where a low efficacy was reported. ${ }^{21-24}$ 
Neoadjuvant icotinib was generally well tolerated, with rash $(43.3 \%)$, skin dryness $(34.3 \%)$, and diarrhea (13.4\%) as the most common adverse reactions. All toxicities were mild (ie, at grade 1 or 2). Icotinib was administrated until the day before surgery, and the main change was that it became more difficult to separate vessels and vascular fragility increased; however, these changes did not significantly influence the operational difficulty and wound healing processes.

\section{Conclusion}

The role of EGFR-TKIs in neoadjuvant therapy is not well studied. To our knowledge, most trials had small sample size and limited study period. The current study demonstrated the efficacy and tolerability of short-term neoadjuvant therapy with icotinib in patients living with early-stage NSCLC, especially among those with common EGFR mutation type. Future trials should incorporate targeted therapies as part of a neoadjuvant strategy based on molecular profile to provide sufficient consolidated evidence to improve clinical practice.

\section{Disclosure}

The authors report no conflicts of interest in this work.

\section{References}

1. Chen WQ, Zheng RS, Zeng HM, et al. Report of cancer incidence and mortality in China, 2011. China Cancer. 2015;24:1-10.

2. Le Chevalier T. Adjuvant chemotherapy for resectable non-small cell lung cancer: where is it going? Ann Oncol. 2010;21(Suppl 7): vii196-vii198.

3. Douillard JY, Tribodet H, Aubert D, et al. Adjuvant cisplatin and vinorelbine for completely resected non-small cell lung cancer: subgroup analysis of the lung adjuvant cisplatin evaluation. J Thorac Oncol.2010; 5:220-228.

4. Burdett S, Rydzewska LH, Tierney JF. Pre-operative chemotherapy improves survival and reduces recurrence in operable non-small cell lung cancer: preliminary results of a systematic review and meta-analysis of individual patient data from 13 randomised trials. J Thor Oncol. 2011; 6(Suppl 2):374-375.

5. Haspinger ER, Agustoni F, Torri V, et al. Is there evidence for different effects among EGFR-TKIs? Systematic review and meta-analysis of EGFR tyrosine kinase inhibitors (TKIs) versus chemotherapy as firstline treatment for patients harboring EGFR mutations. Crit Rev Oncol Hematol. 2015;94:213-227.

6. National Comprehensive Cancer Network. Non-small cell lung cancer v.5.2015. Available from: http://www.nccn.org/professionals/ physician_gls/pdf/nscl.pdf. Accessed September 3, 2015.

7. Reck M, Popat S, Reinmuth N, et al. Metastatic non-small-cell lung cancer (NSCLC): ESMO Clinical Practice Guidelines for diagnosis, treatment and follow-up. Ann Oncol. 2014;25(Suppl 3):iii27-iii39.
8. Shi Y, Zhang L, Liu X, et al. Icotinib versus gefitinib in previously treated advanced non-small-cell lung cancer (ICOGEN): a randomized, doubleblind phase 3 non-inferiority trial. Lancet Oncol. 2013;14:953-961.

9. Eisenhauer EA, Therasse P, Bogaerts J, et al. New response evaluation criteria in solid tumours: revised RECIST guideline (version 1.1). Eur J Cancer. 2009;45:228-247.

10. National Cancer Institute. Cancer Therapy Evaluation Program: Common Terminology Criteria for Adverse Events, version 4.0. Available from: http://ctep.cancer.gov/protocolDevelopment/electronic_applications/ ctc.htm. Accessed June 14, 2010.

11. Lynch TJ, Bell DW, Sordella R, et al. Activating mutations in the epidermal growth factor receptor underlying responsiveness of non-small-cell lung cancer to gefitinib. N Engl J Med. 2004;350:2129-2139.

12. Lara-Guerra H, Waddell TK, Salvarrey MA, et al. Phase II study of preoperative gefitinib in clinical stage I non-small-cell lung cancer. J Clin Oncol. 2009;27:6229-6236.

13. Schaake EE, Kappers I, Codrington HE, et al. Tumor response and toxicity of neoadjuvant erlotinib in patients with early-stage non-small-cell lung cancer. J Clin Oncol. 2012;30:2731-2738.

14. Scagliotti GV, Pastorino U, Vansteenkiste JF, et al. Randomized phase III study of surgery alone or surgery plus preoperative cisplatin and gemcitabine in stages IB to IIIA non-small-cell lung cancer. J Clin Oncol. 2012; 30:172-178.

15. Pisters KM, Vallières E, Crowley JJ, et al. Surgery with or without preoperative paclitaxel and carboplatin in early-stage non-small-cell lung cancer: Southwest Oncology Group Trial S9900, an intergroup, randomized, phase III trial. J Clin Oncol. 2010;28:1843-1849.

16. Felip E, Rosell R, Maestre JA, et al. Preoperative chemotherapy plus surgery versus surgery plus adjuvant chemotherapy versus surgery alone in early-stage non-small-cell lung cancer. J Clin Oncol. 2010;28: 3138-3145.

17. Jackman DM, Yeap BY, Sequist L, et al. Exon 19 deletion mutations of epidermal growth factor receptor are associated with prolonged survival in non-small cell lung cancer patients treated with gefitinib or erlotinib. Clin Cancer Res. 2006;12:3908-3914.

18. Riely GJ, Pao W, Pham D, et al. Clinical course of patients with nonsmall cell lung cancer and epidermal growth factor receptor exon 19 and exon 21 mutations treated with gefitinib or erlotinib. Clin Cancer Res. 2006;12:839-844.

19. Jänne PA, Wang X, Socinski MA, et al. Randomized phase II trial of erlotinib alone or with carboplatin and paclitaxel in patients who were never or light former smokers with advanced lung adenocarcinoma: CALGB 30406 trial. J Clin Oncol. 2012;30(17):2063-2069.

20. Yang JC, Wu YL, Schuler M, et al. Afatinib versus cisplatin-based chemotherapy for EGFR mutation-positive lung adenocarcinoma (LUXLung 3 and LUX-Lung 6): analysis of overall survival data from two randomised, phase 3 trials. Lancet Oncol. 2015;16:141-151.

21. Yasuda H, Kobayashi S, Costa DB. EGFR exon 20 insertion mutations in non-small-cell lung cancer: preclinical data and clinical implications. Lancet Oncol. 2012;13:e23-e31.

22. Beau-Faller M, Prim N, Ruppert AM, et al. Rare EGFR exon 18 and exon 20 mutations in non-small-cell lung cancer on 10117 patients: a multicentre observational study by the French ERMETIC-IFCT network. Ann Oncol. 2014;25:126-131.

23. Arcila ME, Nafa K, Chaft JE, et al. EGFR exon 20 insertion mutations in lung adenocarcinomas: prevalence, molecular heterogeneity, and clinicopathologic characteristics. Mol Cancer Ther. 2013;12:220-229.

24. Wu JY, Wu SG, Yang CH, et al. Lung cancer with epidermal growth factor receptor exon 20 mutations is associated with poor gefitinib treatment response. Clin Cancer Res. 2008;14:4877-4882. 
OncoTargets and Therapy

\section{Publish your work in this journal}

OncoTargets and Therapy is an international, peer-reviewed, open access journal focusing on the pathological basis of all cancers, potential targets for therapy and treatment protocols employed to improve the management of cancer patients. The journal also focuses on the impact of management programs and new therapeutic agents and protocols on

patient perspectives such as quality of life, adherence and satisfaction. The manuscript management system is completely online and includes a very quick and fair peer-review system, which is all easy to use. Visit http://www.dovepress.com/testimonials.php to read real quotes from published authors.

Submit your manuscript here: http://www.dovepress.com/oncotargets-and-therapy-journal 